\title{
Ethnobotanical study on herbal market at the Dragon Boat Festival of Chuanqing people in China
}

Qinghe Wang ${ }^{1}$, Ling Zhao ${ }^{1}$, Chi Gao ${ }^{1}$, Jiawen Zhao ${ }^{2}$, Zixuan Ren ${ }^{2}$, Yuxiang Shen ${ }^{3}$, Ruyu Yao ${ }^{4^{*}}$ (D) and Hongxiang Yin ${ }^{2 *}$

\begin{abstract}
Background: The Chuanqing people (穿青人) are a linguistic group native to the Guizhou Province of China, with unique culture and rich knowledge of traditional medicinal plants. Herbal market at Dragon Boat Festival (DBF) plays an important role in the inheritance of traditional medicinal knowledge among the Chuanqing people. This study aims to record the profile of medicinal plants of the Chuanqing people, discuss the dilemmas faced by their inheritance, and propose some strategies for passing down information, which is critical for the inheritance and protection of the Chuanqing people's traditional medical knowledge.

Methods: Data were collected through key informants and semi-structured interviews and free listing. Collected voucher specimens were identified using by botanical taxonomy method and deposited in the herbarium. Data were analyzed through use-value (UV) and cultural importance index (Cl) values. Medicinal plants were compared with the Information System of Chinese Rare and Endangered Plants of the Chinese Academy of Sciences. Results were compared with the Pharmacopoeia of the People's Republic of China (ChP), the Quality Standard of Traditional Chinese Medicine and National Medicine in Guizhou Province (QSG), and traditional medicines of Southeast Asian countries.
\end{abstract}

Results: A total of 102 species from 53 families and 92 genera were recorded, with Orchidaceae and Asparagaceae (six species each), and Berberidaceae and Asteraceae (five species each) as the predominant families. The whole plant (36\%) was the most common medicinal part. Decoction (44\%) was the most common preparation method. Seventy-one investigated human ailments were grouped into 12 categories. Diseases of the musculoskeletal system (34 mentions) were most frequently mentioned in this study. Moreover, the most frequently used taxon was Hedera sinensis (Tobler) Hand.-Mazz. (UV and $\mathrm{Cl}=0.29$ ). The Chuanqing people's medicine was highly similar to ChP and QSG. In comparison with Southeast Asian countries' traditional medicines, except for the same preparation methods, the similarities in terms of medicinal ingredients, plants, and disease treatment were very low.

(Continued on next page)

\footnotetext{
* Correspondence: yry0255@126.com; hongxiangy@126.com

${ }^{4}$ Institute of Medicinal Plant Development, Chinese Academy of Medical

Sciences \& Peking Union Medical College, Beijing 10093, China

${ }^{2}$ School of Ethnic Medicine, Chengdu University of Traditional Chinese

Medicine, Chengdu 61137, China

Full list of author information is available at the end of the article
}

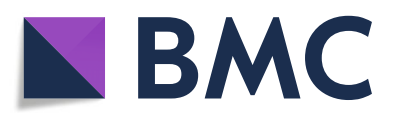

(c) The Author(s). 2021 Open Access This article is licensed under a Creative Commons Attribution 4.0 International License, which permits use, sharing, adaptation, distribution and reproduction in any medium or format, as long as you give appropriate credit to the original author(s) and the source, provide a link to the Creative Commons licence, and indicate if changes were made. The images or other third party material in this article are included in the article's Creative Commons licence, unless indicated otherwise in a credit line to the material. If material is not included in the article's Creative Commons licence and your intended use is not permitted by statutory regulation or exceeds the permitted use, you will need to obtain permission directly from the copyright holder. To view a copy of this licence, visit http://creativecommons.org/licenses/by/4.0/ The Creative Commons Public Domain Dedication waiver (http://creativecommons.org/publicdomain/zero/1.0/) applies to the data made available in this article, unless otherwise stated in a credit line to the data. 


\begin{abstract}
(Continued from previous page)
Conclusions: The herbal market at the DBF is an important platform for exchanging knowledge about the Chuanqing people's traditional medicinal plants. The Chuanqing people's traditional medicine is facing many challenges to its inheritance and development. To solve these problems, this study highlights the traditional medicinal knowledge of the Chuanqing people, providing basic data for further research and protection of minority medicine.
\end{abstract}

Keywords: Linguistic group, Ethnobotany, Medicinal plant, Nayong County, Traditional knowledge

\section{Background}

In most developing countries, medicinal plants constitute the main materia medica for 70 to $95 \%$ of citizens [1-3]. Because of outdated medical facilities and unaffordable medical expenses, traditional medicinal plants have become the first choice or supplement for medical alternatives in most developing countries [4, 5]. In developed countries, increasing numbers of people are also utilizing traditional medicinal plants to treat diseases. With today's globalized development, traditional medicine has kept pace with the times, which is of great value for the protection of human health. In 2015, for example, Tu Youyou won the Nobel Prize in Physiology or Medicine for the discovery of artemisinin, an extract from traditional Chinese medicine (TCM) Artemisia annua L. In 2018, China's Tibetan medicinal bathing was listed as Intangible Cultural Heritage. To prevent COVID-19, the National Health Protection Commission of China had written the proprietary Chinese medicine Lianhua Qingwen Capsule and Qingfei Paidu Decoction into the guidelines for clinical diagnosis and treatment. All these cases have shown the important role played by traditional medicine in modern society. At the same time, Chinese ethnic medicines have also attracted the attention of researchers [6-11].

Furthermore, as the value of medicinal plants has risen, the traditional market has become an important source of income for citizens. Many studies of traditional herbal markets have been made conducted, such as the herbal markets in Africa and Europe [12, 13], and Hunan [14, 15], and Yunnan Provinces in China [16, 17]. Herbs collected at the Dragon Boat Festivals (DBFs) in China are considered to be of higher quality than those collected at other times [18]. Consequently, people will take advantage of DBFs to collect herbs for use and sale. In Southwest China, the DBFs have become a unique opportunity for local farmers to exhibit and sell local medical resources. Gatherings at DBFs also represent communication platforms for local medical knowledge and experience. The herbal market at the Chuanqing people's DBF in Guizhou is just such a typical case.

The Chuanqing people are a native linguistic group with a large population in China. They live mainly in Nayong County and Zhijin County of Guizhou Province [19]. According to the genetic relationship, the Chuanqing people are similar to the south Han, Miao, She, and Tujia ethnicities $[20,21]$; it is a community with multiple ethnic groups. Every year, on the fifth day of the fifth month of the Chinese lunar calendar, the Chuanqing people in Nayong County prepare a grand herbal market at the DBF. People trade herbs and share their experiences with using herbs and treating diseases at the DBF herbal market. The herbal market has thus become an integral part of the medical culture of the Chuanqing people. This spontaneous traditional activity plays an important role in the inheritance and protection of local traditional medicinal knowledge and sustainable development.

Thus far, there has been a lack of ethnobotanical research on the traditional medicinal plant knowledge of the Chuanqing people in China. Therefore, based on the theories and methods of ethnobotany, this study investigated the medicinal plants of the Chuanqing people in Guizhou to answer three questions: (i) what is the profile of the Chuanqing people's traditional medicinal knowledge? (ii) what are the differences and similarities between their traditional medicinal plants and the Pharmacopoeia of the People's Republic of China (ChP) [22], the Quality Standard of TCM and National Medicine in Guizhou Province (QSG) [23], and traditional medicines of Southeast Asian countries? and (iii) what are the dilemmas and problems faced by the Chuanqing people related to the inheritance and development of traditional medicine knowledge and practices?

\section{Methods \\ Location of the study site}

The study was conducted in Nayong County of Guizhou Province, China $\left(105^{\circ} 38^{\prime} 04^{\prime \prime} \mathrm{E}\right.$ and $27^{\circ} 05^{\prime} 54^{\prime \prime} \mathrm{N}$ ) (Fig. $1)$. The area has a wide karst landform, which is the transition zone from the Yunnan-Guizhou Plateau to the Wumeng Mountain area. The elevation ranges from 1050 to $2476 \mathrm{~m}$, with an average elevation of $1685 \mathrm{~m}$. The mean annual temperature is $13.7{ }^{\circ} \mathrm{C}$, the mean sunshine duration is $1346.3 \mathrm{~h}$, and the mean annual precipitation is $1203.0 \mathrm{~mm}$. According to official data, Nayong County is a vegetation transition zone and has a northern subtropical humid monsoon climate. The vegetation of the karst area is composed of evergreen broad-leaved forest, evergreen deciduous mixed forest, and deciduous broad- 


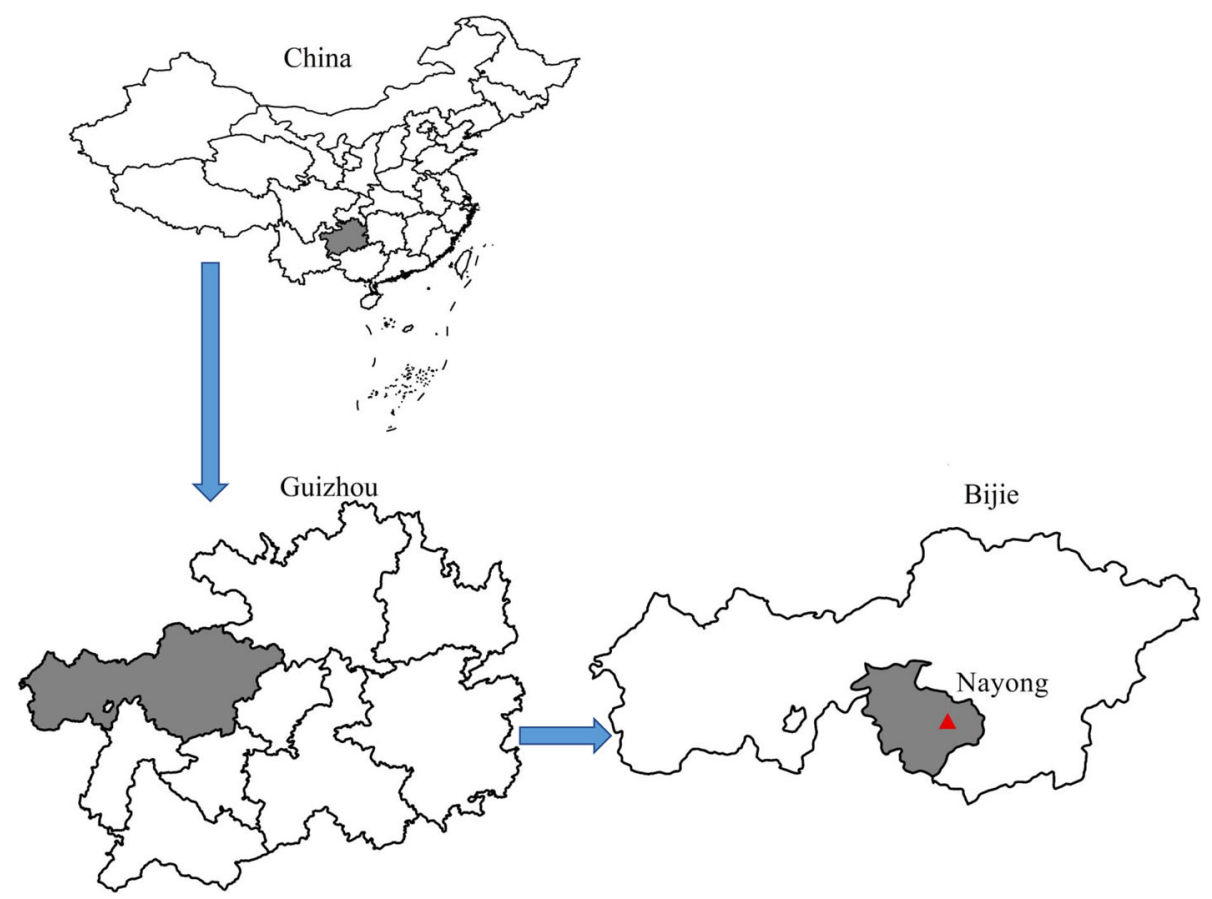

Fig. 1 The location of Nayong County, Guizhou Province, China

leaved forest [24]. The vegetation is luxuriant, and the forest coverage rate is $47.05 \%$. A total of 1857 plant species from 277 families and 772 genera, in addition to 174 species of wild vertebrates from 56 families and 26 orders, have been recorded in Nayong County. Nayong County is rich in biodiversity; it has a provincial dove tree nature reserve, which is home to rare animals and plants, such as Tetracentron sinense Oliv., Prionodon pardicolor Hodgson, and Tylototriton kweichowensis Fang and Chang [25, 26]. This diversity is conducive to the survey of medicinal ethnobotany and specimen collection. The county is located in the core distribution area of the Chuanqing people. The traditional customs and habits of the Chuanqing people are well preserved. The ethnic characteristics of traditional culture and medical knowledge are distinct and representative. The location of the herbal market at the DBF is centered on the Qianwanjia Agriculture Trade Fairs and extends to two streets, Xinjie Road and Gongmao Road in Nayong County.

\section{Ethnobotanical data collection}

This survey was conducted from June 2018 to June 2019 at the DBF. In this survey, 52 informants were investigated, of whom 33 were males and 19 were females, aged 25 to 80 years, with an average age of 56 years. The medicinal materials sold included one to 25 kinds per informant, $90 \%$ of which were wild medicinal materials, obtained mainly through self-collection. Key informant interviews, semi-structured interviews, and free listing were used to obtain information about the ages of the vendors, the names of the medicinal materials, the medicinal parts, the preparation methods, and the functions, indications, sources and collection methods of the medicinal materials (Appendix). After collecting the basic information, the medicinal materials were bought from the vendors and used as specimens. Each exsiccata was identified according to the Flora of China [27] and Flora of Guizhou [28]. The plant families and species followed the World Flora Online (http://www.worldfloraonline.org.), which was used to provide a uniform nomenclature after identification. All the voucher specimens were identified by Hongxiang Yin, an Associate Professor of the Chengdu University of TCM and Yuxiang Shen, an Associate Professor of the Anshun College. The voucher specimens were preserved at the Specimen Center of Chengdu University of TCM (CDCM). At the same time, the collected plant information was compared with the ChP [22], QSG [23], and the traditional medicines in the countries of Southeast Asia. The protected status of the collected medicinal plants was identified by the Information System of Chinese Rare and Endangered Plants [29] of the Chinese Academy of Sciences.

\section{Data analysis}

The quantitative statistical indexes of ethnobotany were calculated by Microsoft Excel 2010, including the usevalue (UV) and cultural importance index (CI). According to the International Classification of Primary Care (ICPC- 
2, http://www.who.int/classification/icd/adaptations/ icpc2/en/), 71 diseases of the Chuanqing people in Nayong County were classified into 12 categories. The UV of a medical plant species, a quantitative parameter that demonstrates the relative importance of species known by local people, was also calculated as follows:

$$
\mathrm{UV}=\sum \frac{\mathrm{UP}}{n}
$$

where UP refers to the number of mentions per species by each informant and $n$ is the total number of informants [30].

The CI was used to indicate the spread of the use (number of informants) of each species as well as to determine the diversity of uses.

$$
\mathrm{CI}_{\mathrm{S}}=\sum_{u=u_{1}}^{u_{\mathrm{NC}}} \sum_{i=i_{1}}^{\mathrm{i}_{N}} \frac{\mathrm{UR}_{u i}}{N}
$$

where $N$ is the total number of informants and $\mathrm{NC}$ is the total number of use categories. $\mathrm{CI}$ is the sum of the proportion of informants who mentioned each of the use categories for a given species. A higher CI value indicates more uses of a species [31].

\section{Results}

\section{Age and gender structure of the mastery of medical knowledge}

According to the survey, the number of medicinal materials that were mastered by men was much higher than that mastered by women (Fig. 2). The data showed that 299 herbs were provided by men, whereas only 128 herbs were provided by women, less than half of that provided by men. Additionally, men aged $61-80$ years provided the most medicinal materials, whereas men aged 21-40 years provided the least (Fig. 2). Women aged 41-60 years provided the greatest amount of medicinal materials, whereas women aged $21-40$ years provided the least (Fig. 2). The knowledge of medicinal plants of the Chuanqing people was mainly mastered by middle-aged and older males (aged 41-80 years).

\section{Taxonomic characteristics of the medicinal plants}

A total of 102 medicinal plant species belonging to 92 genera and 53 families were provided by the Chuanqing people (Fig. 3). The dominant families of the Chuanqing people's medicinal plants were Orchidaceae and Asparagaceae (six species each), including species such as Bletilla striata (Thunb.) Rchb.f., Reineckea carnea (Andrews) Kunth, and Asparagus filicinus Buch.-Ham. ex D.Don. Following by Berberidaceae and Asteraceae (five species each), including species such as Senecio analogus DC. and Dysosma delavayi (Franch.) Hu., and Apocynaceae, Ranunculaceae, Rosaceae, and Polygonaceae (four species each). The remaining families were represented by three or fewer entities.

\section{Analysis of medicinal parts}

Sixteen parts of medicinal plants were used by the Chuanqing people, of which the whole plant was the most common (36\%), such as Dendrobium catenatum Lindl. and Taraxacum mongolicum Hand. - Mazz., etc. This was followed by roots $(25 \%)$, rhizomes $(12 \%)$, root tubers $(9 \%)$, leaves $(4 \%)$, fruits $(2 \%)$, flowers $(2 \%)$, stems $(2 \%)$, aerial parts $(2 \%)$ and others (7\%) (Fig. 4). The proportion of underground parts that were used as medicinal parts reached $46 \%$.

\section{Preparation methods}

Eighteen preparation methods of the Chuanqing people were recorded. Decoction (44\%) was the most commonly used preparation method, as observed for Disporopsis fuscopicta Hance, Verbena officinalis L., and Polygonum

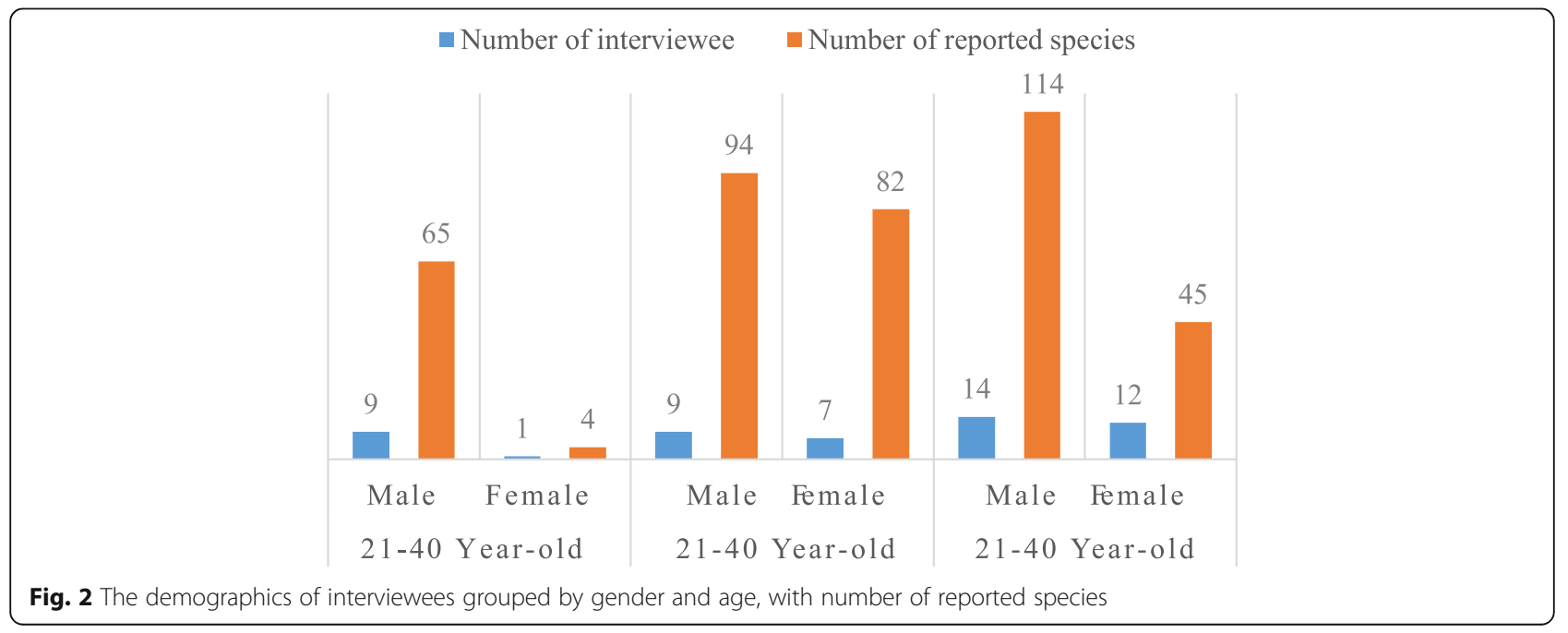




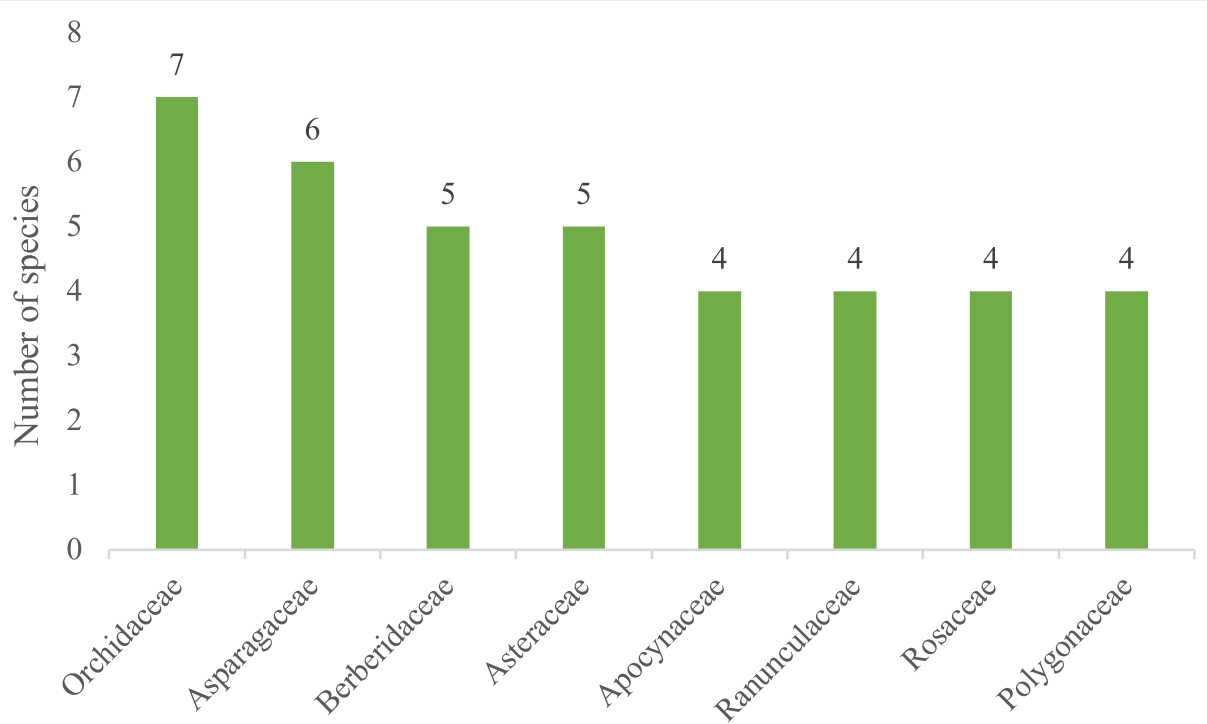

Fig. 3 The dominant medicinal plant families and number of species at the herbal market of the DBF

aviculare L. This was followed by alcohol maceration (19\%), bath $(6 \%)$, cooked with pork (6\%), mashed $(5 \%)$, cooked with chicken (3\%), powdered with boiled water (3\%), steamed with honey $(3 \%)$, sliced $(2 \%)$, vinegar maceration (2\%), and others (6\%) (Fig. 5). Additionally, there were some special medical methods used by the Chuanqing people, such as souping with glutinous rice and firing with eggs.

\section{Functions and indications}

According to the International Classification of Primary Care (ICPC-2, https://www.who.int/classifications/icd/ adaptations/icpc2/en/), the herbs sold at the herbal market were used to treat 71 human ailments, which were divided into 12 categories (Table 1). Most medicinal materials were used to treat diseases of the musculoskeletal system (34 mentions), followed by diseases of the digestive system (18 mentions), certain infectious and parasitic diseases (17 mentions), and diseases of the urinary and genital system (16 mentions), diseases of the respiratory system (15 mentions). The remaining categories of aliments were represented by one to five mentions.

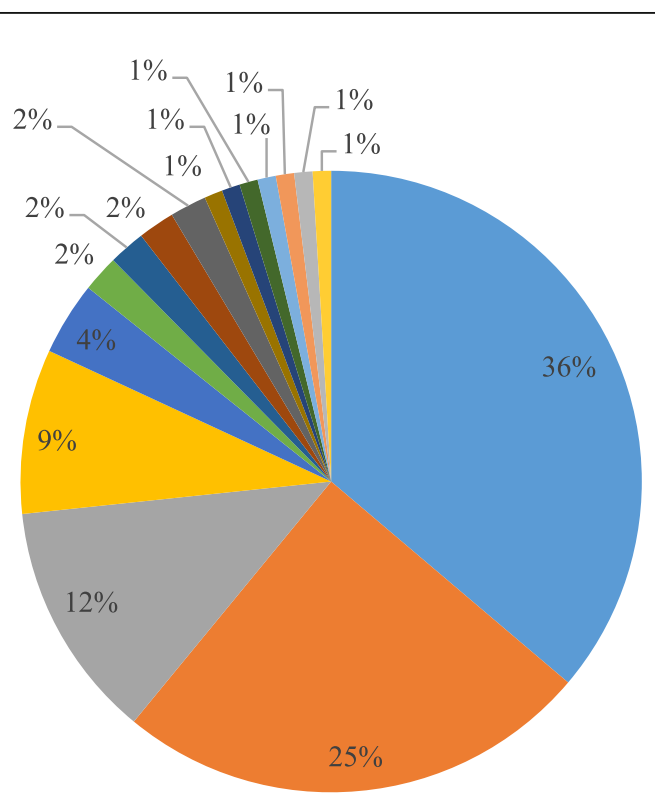

$$
\begin{aligned}
& \text { - Whole plant } \\
& \text { - Roots } \\
& \text { - Rhizomes } \\
& \text { Root tubers } \\
& \text { a Leaves } \\
& \text { aruits } \\
& \text { - Flowers } \\
& \text { - Stems } \\
& \text { - Aerial parts } \\
& \text { - Seeds } \\
& \text { a Thorns } \\
& \text { - Fruiting bodies } \\
& \text { - Bulbs } \\
& \text { - Vines } \\
& \text { - Barks } \\
& \text { - Root barks }
\end{aligned}
$$

Fig. 4 The proportion of medicinal parts at the herbal market of the DBF 


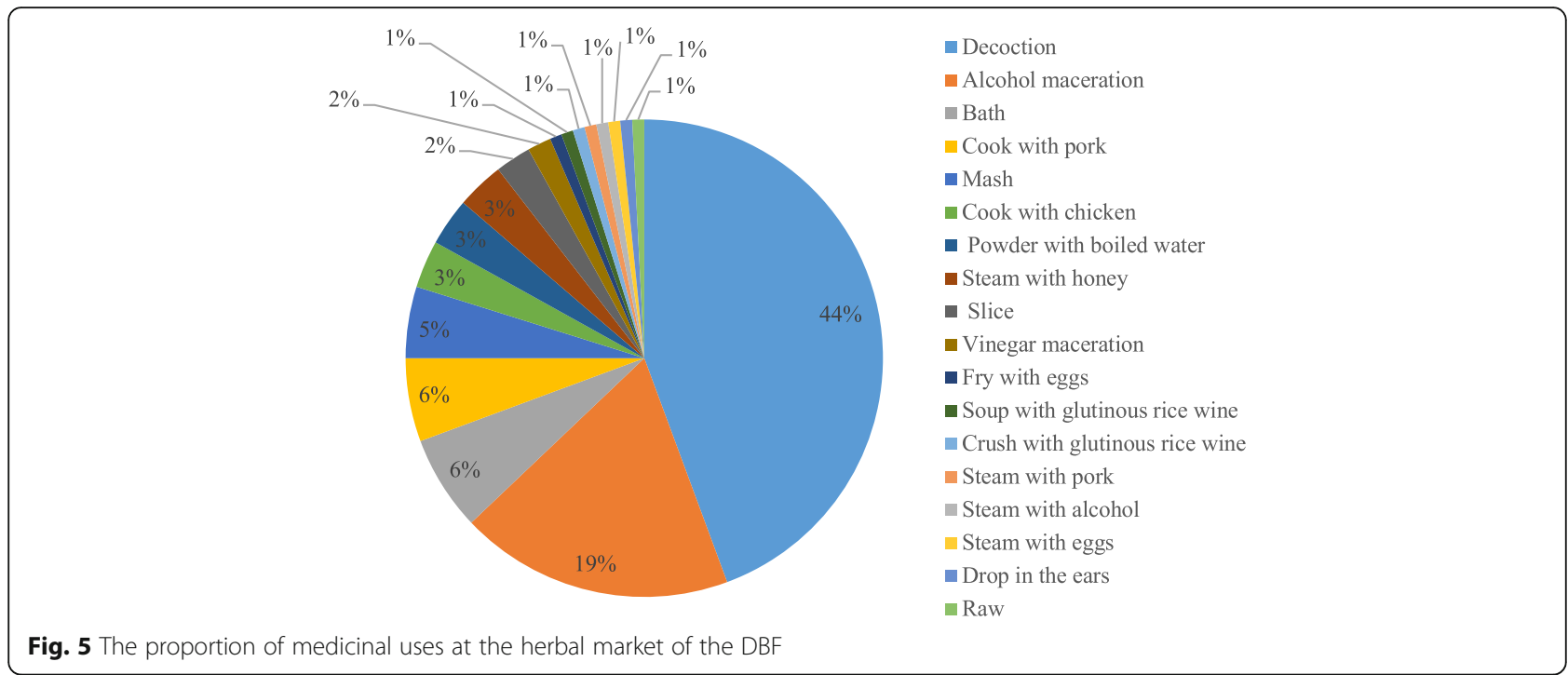

\section{Analysis of the $\mathrm{UV}$ and $\mathrm{Cl}$ values of medicinal plants of the Chuanqing people}

The UV of medicinal plants used by the Chuanqing people ranged from 0.02 to 0.29 , whereas many species had low $\mathrm{UV}$ and $\mathrm{CI}$ values. The UV values of 10 medicinal plants $(\mathrm{UV}=\mathrm{CI}>0.10$ ) were high (Appendix); the highest UV and $\mathrm{CI}$ values were calculated for Hedera sinensis (Tobler) Hand.-Mass. (UV and CI = 0.29), Aconitum carmichaelii Debeaux, Plantago major L., Persicaria capitata (Buch.Ham. ex D.Don) H., Paris polyphylla Sm, and Potentilla discolor Bunge ( $\mathrm{UV}$ and $\mathrm{CI}=0.13$ ) and Geum aleppicum Jacq. (UV and CI $=0.12$ ), and Artemisia argyi H.Lév. \& Vaniot, Epimedium acuminatum Franch., and Lysimachia paridiformis var. stenophylla Franch. $(\mathrm{UV}$ and $\mathrm{CI}=0.10)$.

\section{Analysis of the species with rare and endangered status} A total of 9 medicinal plants were recorded in the Information System of Chinese Rare and Endangered Plants (Table 2 ), and nine species were recorded as nationally protected

Table 1 The number of categories of ailments

\begin{tabular}{ll}
\hline Category & Number \\
\hline Musculoskeletal system & 34 \\
Digestive system & 18 \\
Certain infectious and parasitic diseases & 17 \\
Urinary and genital system & 16 \\
Respiratory system & 15 \\
General & 5 \\
Circulatory system & 5 \\
Neurological system & 3 \\
Blood and blood-forming organs immune system & 2 \\
Ear & 2 \\
Pregnancy and childbearing & 1 \\
Eye & 1 \\
\hline
\end{tabular}

plants. Among them, four species were protected by the Convention on International Trade of Endangered Species of Wild Fauna and Flora (CITES), and five species were recorded in the International Union for Conservation of Nature (IUCN), including least concern (one mention), near threatened (one mention), and vulnerable (three mentions) species. Five medicinal species were endemic to China.

\section{Comparison of the Chuanqing people's medicine with the ChP [22], QSG [23], and traditional medicines in Southeast} Asian countries

Compared with the ChP and QSG, 39 medicinal plants (38\%) were documented by the ChP, 31 (30\%) were documented by the QSG, and 11 species were recorded in the ChP, the QSG, and the Chuanqing people's medicine simultaneously (Appendix). These plants were Aconitum carmichaelii Debeaux, Cynanchum paniculatum (Bunge) Kitag. ex H.Hara, Geum aleppicum Jacq., Gleditsia sinensis Lam., Iris tectorum Maxim, Ligusticum striatum DC., Lysionotus pauciflorus Maxim., Paris polyphylla Sm, Reynoutria multiflora (Thunb.) Moldenke, Sanguisorba officinalis L., and Tinospora sagittata Gagnep.

The traditional medicinal knowledge of the Chuanqing people was compared with findings studies recently conducted in Thailand, Laos, Vietnam, and Myanmar. The differences in the dominant families, medicinal parts, preparation methods, and diseases of traditional medicinal plants were analyzed as follows (Table 3). The results showed that Leguminosae was the dominant family in these four countries, whereas Asparagaceae and Orchidaceae were the most commonly used families by the Chuanqing people. Leaves were the most common medicinal part of the plant used in Thailand, Vietnam, and Myanmar, and roots and rhizomes were the most common medicinal part in Laos, whereas the whole plant was the most common medicinal 
Table 2 Records of the information system of Chinese rare and endangered plants

\begin{tabular}{|c|c|c|c|c|}
\hline Scientific name & National protection & CITES & IUCN & Distribution area \\
\hline Magnolia officinalis Rehder \& E.H.Wilson & (II) & & NT & Only in China \\
\hline Rhodiolayun nanensis (Franch.) S. H. Fu & (II) & & LC & Only in China \\
\hline Pleione yunnanensis (Rolfe) Rolfe & (II) & $\|$ & VU & \\
\hline Cibotium barometz (L.) J. Sm. & (II) & $\|$ & & Only in China \\
\hline Aristolochia tuberosa C. F. Liang et S. M. Hwang & (II) & & VU & Only in China \\
\hline Paris polyphylla Sm & (II) & & & \\
\hline Citrus cavaleriei H. Lév. ex Cavalier & (II) & & & Only in China \\
\hline Taxus wallichiana var. chinensis (Pilg.) Florin & (I) & $\|$ & VU & \\
\hline Gastrodia elata Blume. & (II) & $\|$ & & \\
\hline
\end{tabular}

$N T$ near threatened, $L C$ least concern, $V U$ vulnerable

part used by the Chuanqing people. Decoction was the most common preparation method in these four countries and the Chuanqing people. In terms of disease treatment, digestive system diseases were the most common in Thailand, Laos, and Myanmar, whereas eye diseases were the most common in Laos, and musculoskeletal system diseases were the most common in the Chuanqing people.

Table 3 lists listed in the table were the two most frequently used families, the two most frequently used medicinal parts, one of the most frequently used preparation methods, and the three most frequently treated diseases in the four countries.

\section{Discussion}

\section{The knowledge of traditional medicinal plants of the} Chuanqing people

Traditional medicinal knowledge of the Chuanqing people was mastered mainly by men aged $61-80$ years (Fig. 2). According to the data of the National Bureau of Statistics, in 2010 , the illiteracy rate of men in the rural areas was $29 \%$, and that of women was $71 \%$. Men who received more education might develop more knowledge about medicinal plants. Moreover, the family collaboration model in the local Chuanqing people's areas was "men work outside and women do housework" [44], so men had more opportunities to identify and collect medicinal plants in the field.

The main families of medicinal plants used by the Chuanqing people were the Orchidaceae and Asparagaceae families. First, as one of the most typical karst areas in the world, Guizhou's unique geographical location and complex natural environment provided suitable conditions for wild orchids [45]. There are 1240 species of orchids in 171 genera in China, of which 343 species of 82 genera were used for medicinal purposes [46, 47]. Additionally, most plants in Asparagaceae, such as Polygonatum kingianum Collett \& Hemsl. and Asparagus filicinus Buch.-Ham. ex D.Don were used frequently because their thick root tubers were attractive to herb collectors. Second, Orchidaceae and Asparagaceae plants such as Bletilla striata (Thunb.) Rchb.f., Gastrodia elata Blume., and Polygonatum kingianum Collett \& Hemsl. were widely used in TCM. These plants were traditional Chinese herbal medicines are commonly used by people of Han nationality. Therefore, a large amount of TCM was used by the Chuanqing people as they had long been influenced by the traditional Chinese medical system.

The underground plant parts (the sum of roots, rhizomes, and root tubers) used in the Chuanqing people traditional medicine accounted for $46 \%$. Therefore, why is the proportion of underground parts of medicinal plants used by the Chuanqing people so high? Roots, rhizomes, and tubers were frequently used as medicinal parts in TCM; more than one fourth of the medicinal plants added in over 400 preparations were derived from roots and/or rhizomes [48]. The whole plant, which accounted for $36 \%$, was commonly used for medicinal purposes because the whole plant was easy to obtain and convenient to use by local people.

Decoction (44\%) was the most common preparation method used by the Chuanqing people. Decoction was also the most commonly used TCM compound dosage form by traditional Chinese doctors, and it was also the longest and most widely used preparation in the history of China [49].

Table 3 Comparison of traditional medicine between Chuanqing and Southeast Asian countries

\begin{tabular}{|c|c|c|c|c|c|}
\hline Country & Families & Medicinal parts & $\begin{array}{l}\text { Preparation } \\
\text { method }\end{array}$ & Diseases & References \\
\hline Thailand & $\begin{array}{l}\text { Leguminosae, } \\
\text { Asteraceae }\end{array}$ & Leaves, stem & Decoction & Digestive system, infections, nutritional disorders & {$[32-35]$} \\
\hline Laos & $\begin{array}{l}\text { Leguminosae, } \\
\text { Zingiberaceae }\end{array}$ & $\begin{array}{l}\text { Roots and rhizomes, woody part } \\
\text { of plants }\end{array}$ & Decoction & $\begin{array}{l}\text { Gastrointestinal conditions, gynecological conditions, and sexually transmitted } \\
\text { diseases skin affections }\end{array}$ & {$[36-38]$} \\
\hline Vietnam & $\begin{array}{l}\text { Asteraceae, } \\
\text { Leguminosae }\end{array}$ & Leaves, roots & Decoction & $\begin{array}{l}\text { Eye diseases, musculoskeletal disorders, endocrine/metabolic and nutritional } \\
\text { disorders }\end{array}$ & {$[39,40]$} \\
\hline Myanmar & $\begin{array}{l}\text { Leguminosae, } \\
\text { Asteraceae }\end{array}$ & Leaves, roots & Decoction & Digestive system, urological, respiratory & {$[41-43]$} \\
\hline
\end{tabular}


Since the decoction method was also the most commonly used preparation method for the Chuanqing people, it can be seen again that their medicine has a long history of being influenced by TCM. Alcohol maceration was the second most common preparation method, accounting for $19 \%$. Alcohol maceration was also a traditional Chinese medicinal preparation, with unique curative effects, a convenient preparation method, and wide application [50]; it was thus widely used. The Chuanqing people also had some other special usages, such as making a soup with glutinous rice wine and steaming with eggs.

Most medicinal materials were used to treat diseases of the musculoskeletal system (34 mentions). For instance, Artemisia argyi H.Lév. \& Vaniot ( $\mathrm{UV}$ and $\mathrm{CI}=0.10)$, Hedera sinensis (Tobler) Hand.-Mazz. (UV and CI $=0.29$ ), and Lysimachia paridiformis var. stenophylla Franch. (UV and $\mathrm{CI}=0.10$ ) were all used to treat rheumatism; Liparis campylostalix Rchb.f., Rhodiola yunnanensis (Franch.) S. $\mathrm{H}$. $\mathrm{Fu}$, and Cynanchum inamoenum (Maxim.) Loes. ex Gilg. \& Loes. were used to treat traumatic injuries. One reason might be that, according to statistics, the diseases with the fastest increase in hospitalization and expenses in 2015 in China were musculoskeletal diseases [51]. Moreover, people who lived in humid climates and engaged in agriculture, typically had a variety of musculoskeletal system diseases, such as rheumatism [52], traumatic injuries, and other diseases, as do the Chuanqing people.

\section{Comparison with ChP, the QSG, and Southeast Asian medicines}

The existing studies on the Chuanqing people showed that they were closely related to the Han and local ethnic groups in Guizhou such as the Miao in their social culture [20, 21, 53] or medical research [54]. Eleven medicinal plants were also recorded in the ChP, the QSG, and the Chuanqing people's medicine simultaneously, suggesting that the diseases treated with medicinal plants by the Chuanqing people were similar to those found among the ChP and the QSG. For example, Aconitum carmichaelii Debeaux was used to treat noxious sores and had the function of restoring yang for resuscitation; Tinospora sagittata Gagnep. was used to treat neck pain, laryngitis, dysentery, and abdominal pain; and Ligusticum striatum DC. was used to relieve pain by people of ChP, QSG, and the Chuanqing people. However, the diseases treated with some medicinal plants of the Chuanqing people were different from those of both ChP and QSG. For example, Cynanchum paniculatum (Bunge) Kitag. ex H.Hara was used to relieve pain in ChP and QSG, but it was used to treat gynecopathy in the Chuanqing people's medicine and some researchers found that it could treat gynecological inflammation disease because of its anti-inflammatory properties [55]. Gleditsia sinensis Lam. was used to treat osteodynia, and arthralgia rather than psychiatric disorders in ChP and QSG, and some studies found that it also had analgesic effects [56]. Lysionotus pauciflorus Maxim. was first found to treat rheumatism, and Paris polyphylla Sm was first found to treat cardiopathy. Sanguisorba officinalis L. was first found to treat diarrhea in Chuanqing people; this treatment had been corroborated in the reports about being used to treat diarrhea of humans and livestock [57-59].

Generally, after thousands of years of development, TCM had formed a mature theoretical system, such as "the theory of Four Qi and Five Flavors, the theory of Visceral Manifestation, and the theory of Yin-Yang and Five Elements." According to our survey, the Chuanqing people's medicine was still in the stage of summarizing specific knowledge and experience, such as circulated in the form of rhymes.

Southwest China is adjacent to the Southeast Asian countries of Vietnam, Laos, Myanmar, and Thailand [60]. Historically, they had often exchanged cultural practices and medicine. The traditional medicines in Southeast Asian countries were deeply influenced by TCM [61-64]. The Chuanqing people in southwestern China were also influenced by traditional Chinese medicine [65]. Therefore, the Chuanqing people and the people of Southeast Asian countries may have certain similarities in their use of medicinal plants. For instance, decoction was the most common preparation method among them because decocting was the most convenient and simplest method. However, there are also differences in their use of traditional medicinal plants. For example, Leguminosae was widely used in traditional medicines in Southeast Asian countries, whereas Asparagiaceae and Orchidaceae were widely used by the Chuanqing people. The reason for this difference was that Leguminosae was widely distributed in tropical flora and available in these countries [32-41]. The area of southwest China populated by the Chuanqing people is a typical karst landform, with the majority of the plants distributed in Asparagaceae and Orchidaceae [4547]. Leaves are frequently used in Southeast Asian countries; because this region has a tropical rainforest climate and many evergreen plants grow up there, the leaves are abundant and easy to obtain. However, the areas in Guizhou Province populated by the Chuanqing people have a northern subtropical monsoon climate, with a high altitude (1050 to $2476 \mathrm{~m}$ ) and four distinct seasons. In autumn and winter, the whole plant and underground parts could be used without leaves. In Southeast Asian countries, the most common diseases treated by traditional plants were diseases of the digestive system. Studies had pointed out that this was mainly related to living conditions, living habits, and sanitation facilities. For example, in the countries of Southeast Asia, people who worked in agriculture and lived in poverty were susceptible to the diseases of the digestive system, such as gastritis and diarrhea [32, 37]. Alcoholism was also a reason for digestive system diseases [41]. The reasons why the Chuanqing people's medicine mainly treats musculoskeletal diseases 
were discussed above. The approaches found in Thailand, Laos, Vietnam, and Myanmar regarding the dominant plant families, medicinal parts, and treatment of diseases of traditional medicine were different than those of the Chuanqing people, with few similarities.

\section{The dilemmas and solution of the Chuanqing people's traditional medicine culture}

The Chuanqing people's traditional medicinal knowledge was mastered by people aged $61-80$ years, leading to the problem of traditional knowledge being concentrated in older members of the community. Additionally, a large number of rural young people have chosen to move to big cities to work and live in recent years, aggravating the problem of the aging population. This demographic development was not conducive to the inheritance and development of the Chuanqing people's knowledge of traditional medicinal. Furthermore, people's lifestyles have been changed by the impact of modern industrial civilization; their medical choices have also been altered because of the popularization of modern medicine. These factors have led to the decline of the social recognition of traditional medical knowledge and the decrease of users of traditional medicinal practices, which further endangers the application and protection of this knowledge. It is important to strengthen the collection and protection of local traditional medicinal knowledge, conduct a comprehensive interview with the older generation of ethnic doctors, and collect and document the diagnoses and treatment methods with ethnic characteristics.

In recent years, with the increasing demand for natural medicines, many wild medicinal materials have been plundered without scientific protections or development measures. For example, uprooting the whole plant and underground parts as the most commonly used in traditional medicine was not conducive to the regeneration of wild plant populations. Moreover, we found cases of people selling wild protected animals and plants, such as Paris polyphylla Sm, Taxus wallichiana var. chinensis (Pilg.) Florin, and Tylototriton kweichowensis Fang and Chang (listed as vulnerable (IUCN, 2012) and as category II state major protected wildlife in China). This indicated that local, rare, wild plant and animal resources have been destroyed and that legal risks are present in the DBF herbal market. In the face of this situation, the government and non-governmental agencies should strengthen the natural protection of wild species by increasing law enforcement and strengthening the popular science education of local communities. For species with significant economic value, scientific institutions should accelerate scientific research on artificial breeding and cultivation, instead of utilizing wild populations.

Because of the lack of modern scientific and technological means and government guidance, the development of industrialized, modernized planning of the Chuanqing people's medicine was almost absent. To a certain extent, this situation led to the loss of cultural knowledge of the Chuanqing people's medicine and the dilemmas of sustainable development. It should be noted that China's DBF was added to the United Nations Educational, Scientific, and Cultural Organization's Intangible Cultural Heritage list in 2009. Moreover, many regions have upgraded traditional ethnic medicinal markets at the DBF into well-known cultural tourism products. For example, the DBF medicinal market of the Zhuang in Jinxi County has been selected as the intangible cultural heritage of the Guangxi Zhuang autonomous region [66], and the Pu'er City of Yunnan Province promoted the local DBF herbal market as a "Baicao Gen Food and Cultural Tourism Festival" [16]. These examples provide arguments for passing down and promoting the traditional medical culture of the Chuanqing people.

\section{Conclusions}

This is the first study to document the traditional medicinal knowledge of the Chuanqing people in China. A total of 102 species from 53 families and 92 genera were recorded to treat 71 human aliments, which were divided into 12 categories. Most medicinal materials were used to treat diseases of the musculoskeletal system (34 mentions). A total of nine medicinal plants were recorded in the Information System of Chinese Rare and Endangered Plants. Many plants with high UV and CI values need more attention and further research. There are some differences and connections among the Chuanqing people's medicine, ChP and QSG. The Chuanqing people and people of the countries of Southeast Asia have many similarities in preparation methods but few low similarities in medicinal families, medicinal parts, and diseases. The DBF herbal market is an important platform for the Chuanqing people to inherit their traditional medicinal knowledge. The Chuanqing people are rich in medicinal plant species, knowledge, and experience, which reflects their own cultural and regional characteristics. The inheritance and development of traditional medicine by the Chuanqing people have faced many difficulties, such as aging, the impact of modern civilization, exhaustion of resources, legal risks, and lack of policy planning. It is, therefore, necessary that more in-depth research on the Chuanqing people's medicinal plants be conducted; the knowledge of traditional medicinal plants is protected by formulating appropriate policies and practices.

\section{Appendix}

$P U$ parts used, $M P$ method of preparation, $M U$ medicinal use, $P R$ pharmacopoeia records, when compared with PR, medicinal plants used by the Pharmacopoeia of the People's Republic of China (ChP) are marked "A", medicinal plants used by the Quality Standard of TCM and National Medicine in Guizhou Province (QSG) are marked "B", and similar use is marked "AB". 


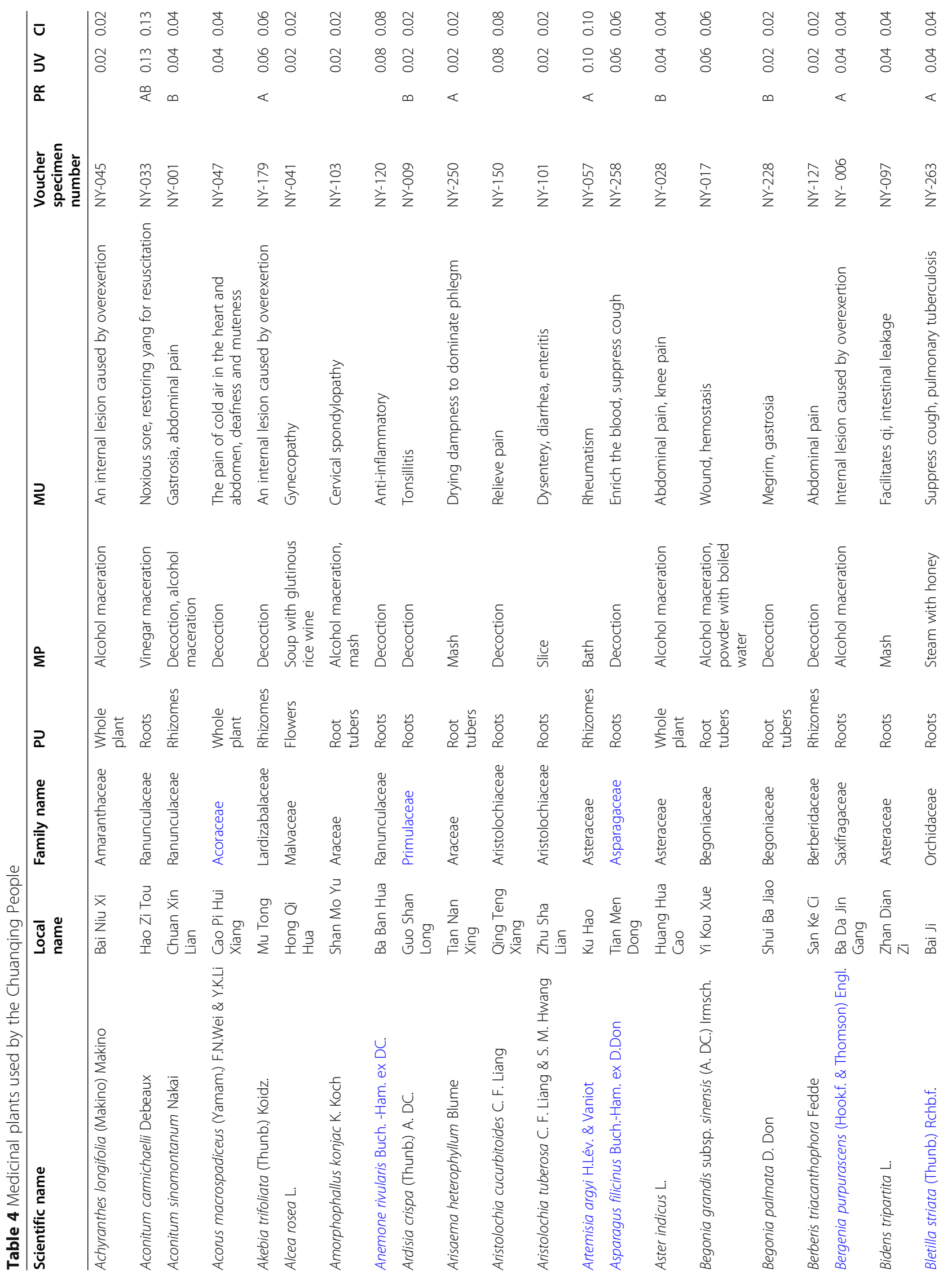




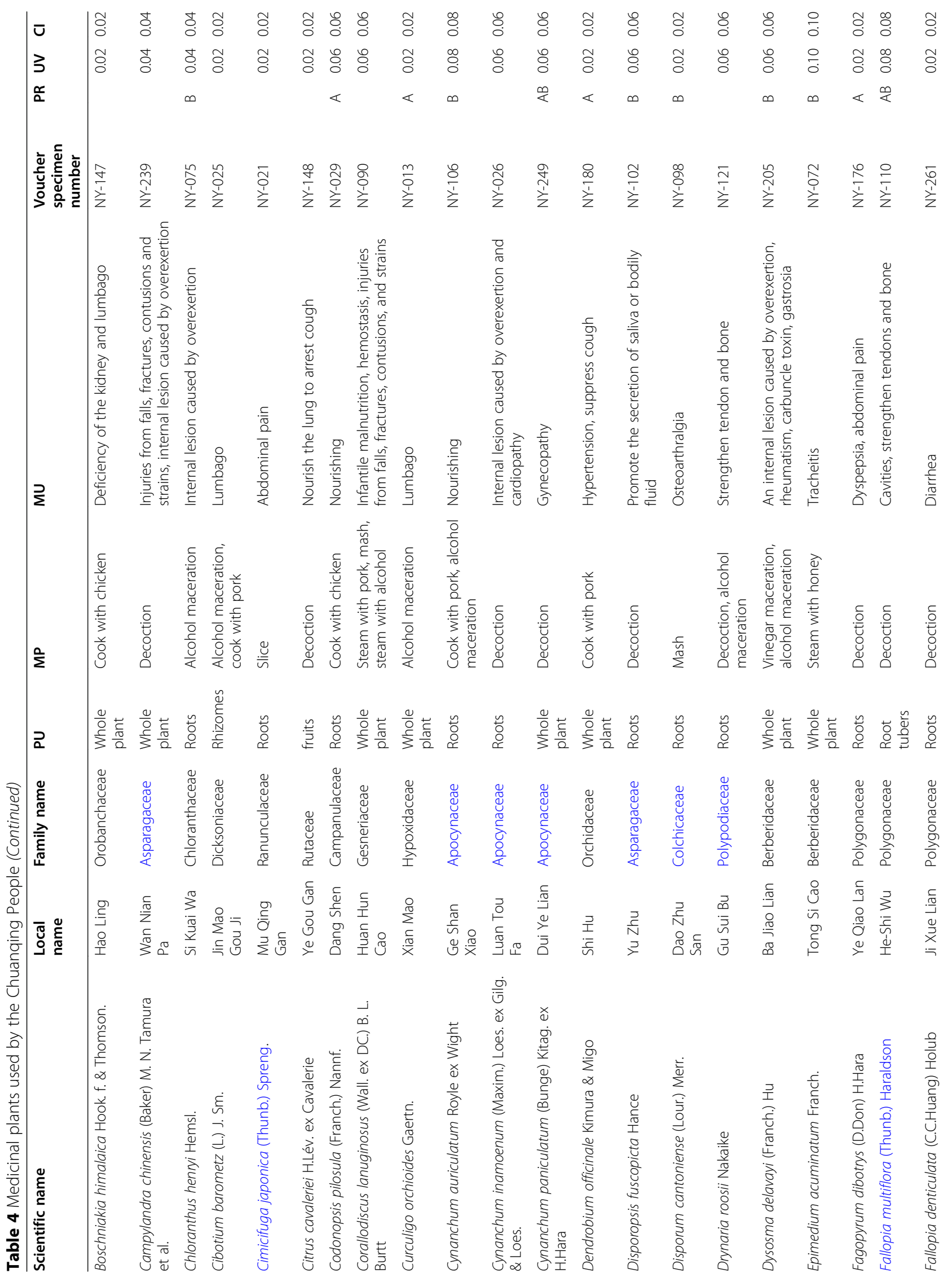




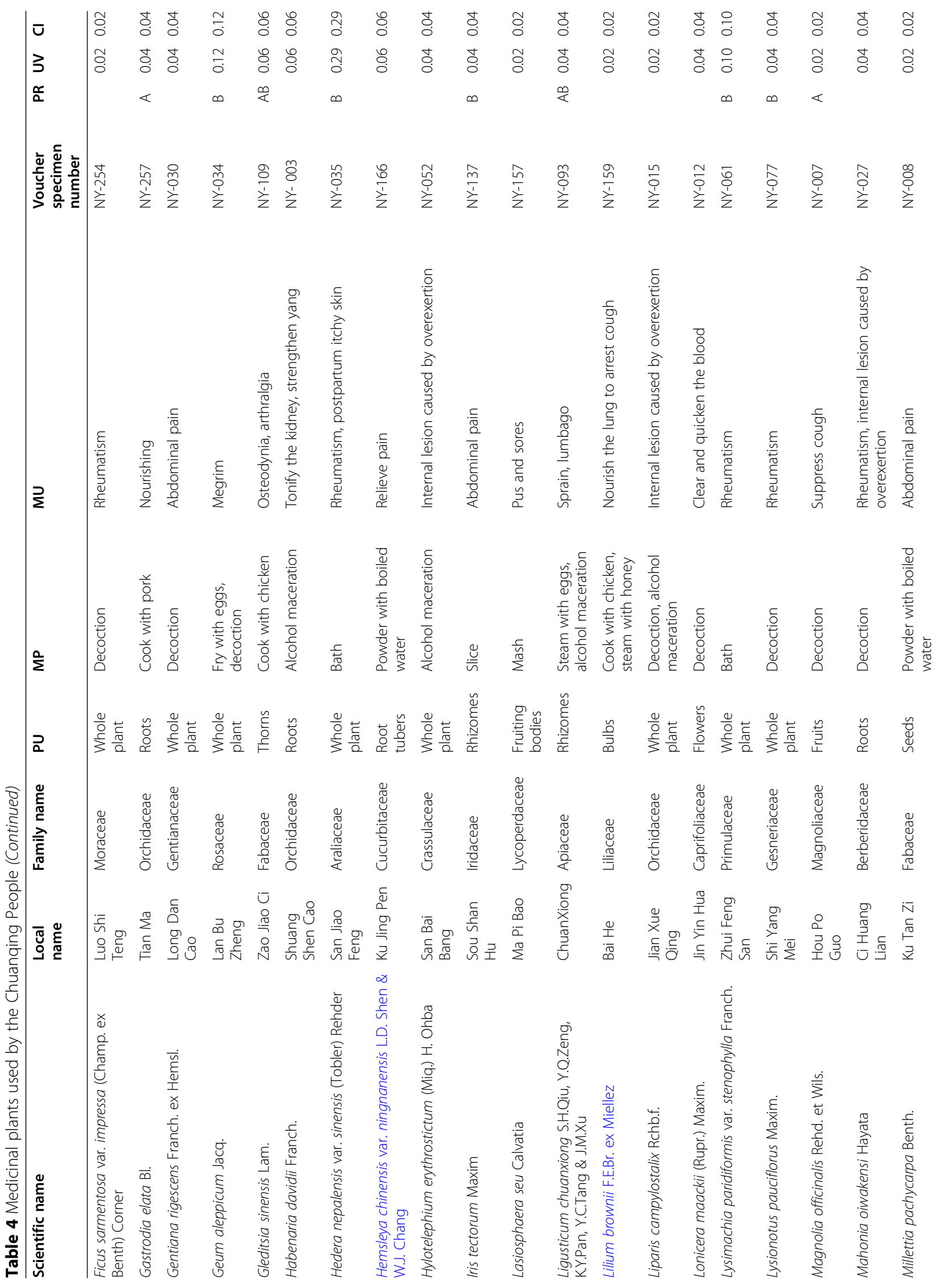




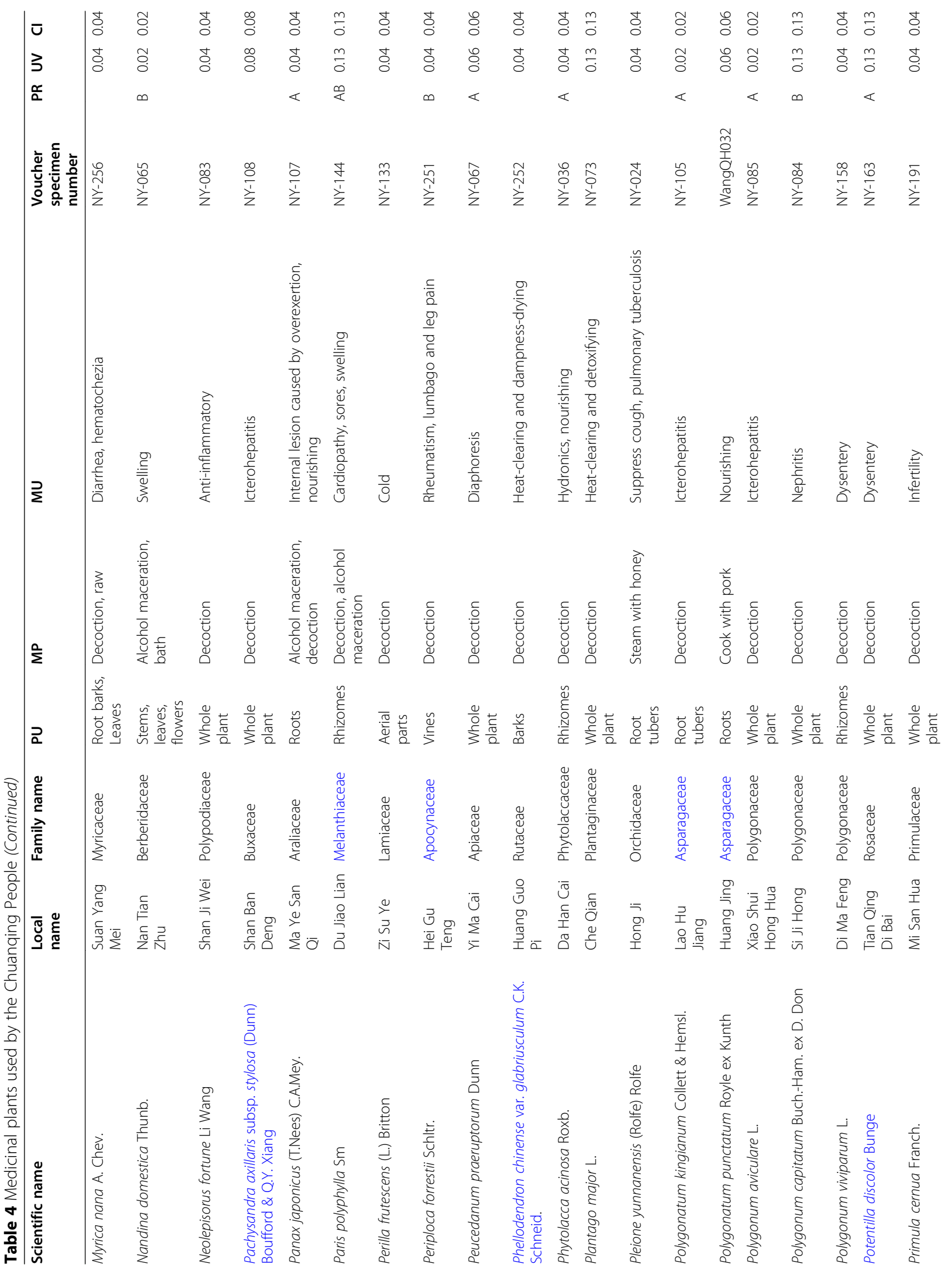




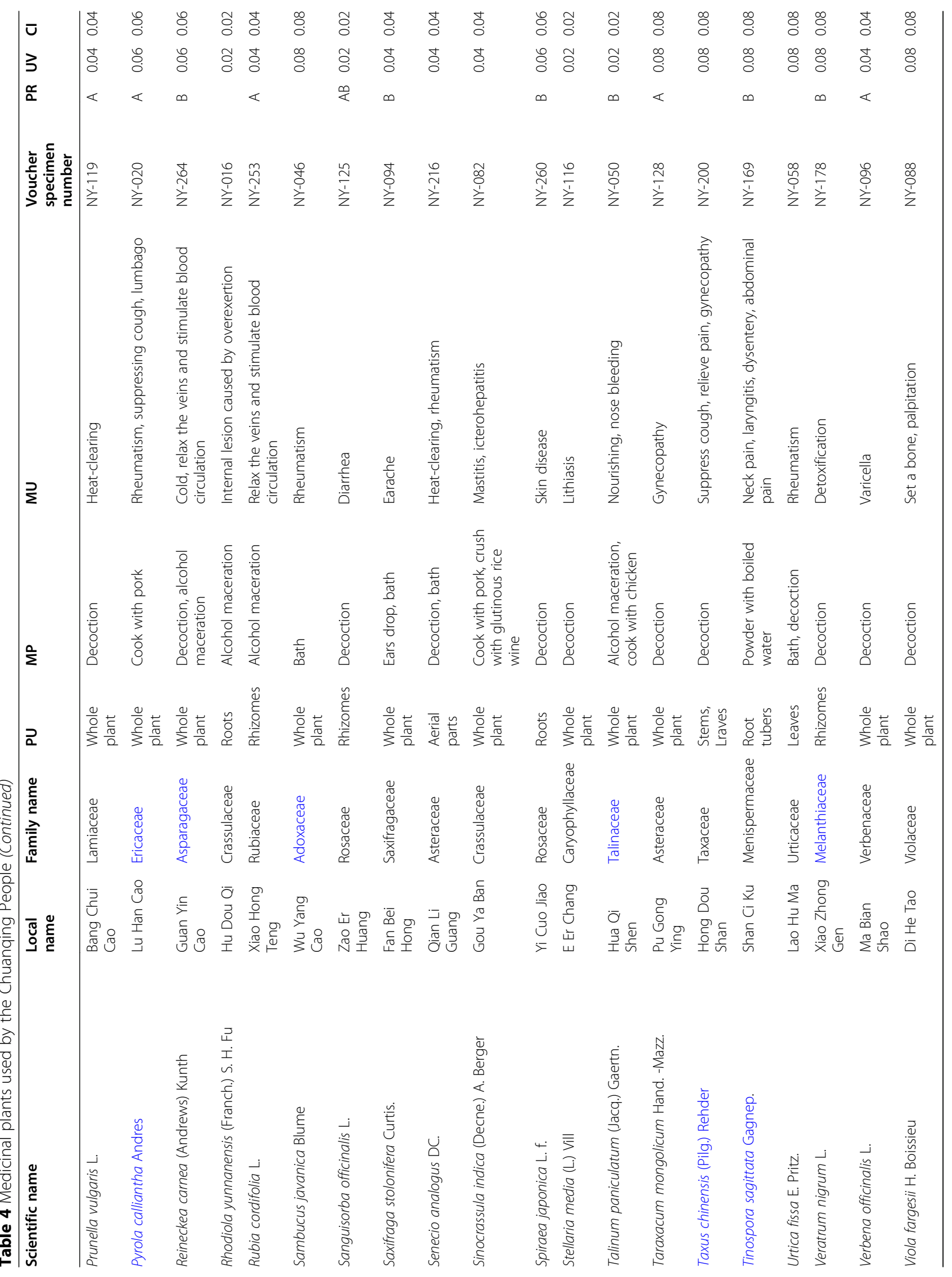




\section{Abbreviations}

DBF: Dragon Boat Festival; TCM: Traditional Chinese medicine; UV: Use-value; Cl: Cultural importance index; ChP: Pharmacopoeia of the People's Republic of China; QSG: The Quality Standard of TCM and National Medicine in Guizhou Province

\section{Acknowledgements}

We are very grateful to all the enthusiastic vendors at the herbal medicine market of the Dragon Boat Festival in Nayong County, Guizhou Province, as well as the local people who came to buy the herbal medicine. We thank Zhengxian Guo for his help in medicine identification and traditional medical knowledge, Ting Kang for her help in the survey, and Keru Wang for her help in the analysis of data.

\section{Authors' contributions}

QHW was involved in the study design, literature search, and analysis of the data. $L Z, C G, J W Z$, and ZXR analyzed part of the data. YXS and HXY provided botanical identifications. HXY and RYY supervised the study and reviewed and revised the manuscript. All authors read and approved the final manuscript.

\section{Funding}

This work was financially supported by the National Natural Science Foundation of China (81573545), Chengdu University of Traditional Chinese Medicine "Xinglin Scholars" Subject Talent Promotion Plan (QNXZ2018039).

\section{Availability of data and materials}

All data generated or analyzed during this study are included in this published article and its supplementary information files.

\section{Declarations}

\section{Ethics approval and consent to participate}

The authors asked for permission from the local authorities and the people interviewed to carry out the study.

\section{Consent for publication}

The people interviewed were informed about the study's objectives and the eventual publication of the information gathered, and they were assured that the informants' identities would remain undisclosed.

\section{Competing interests}

The authors declare no competing interests.

\section{Author details}

'School of Pharmacy, Chengdu University of Traditional Chinese Medicine, Chengdu 61137, China. ${ }^{2}$ School of Ethnic Medicine, Chengdu University of Traditional Chinese Medicine, Chengdu 61137, China. ${ }^{3}$ Anshun College, Anshun 561000, China. ${ }^{4}$ Institute of Medicinal Plant Development, Chinese Academy of Medical Sciences \& Peking Union Medical College, Beijing 10093, China.

\section{Received: 29 July 2020 Accepted: 9 March 2021}

\section{Published online: 23 March 2021}

\section{References}

1. Applequist WL, Brinckmann JA, Cunningham AB, Hart RE, Heinrich M, Katerere DR, van Andel T. Scientists \& apos; Warning on climate change and medicinal plants. Planta Med. 2020;86(1):10-8. https://doi.org/10.1055/a-1 041-3406.

2. World Health Organization. WHO traditional medicine strategy 2002-2005. Geneva: World Health Organization; 2002.

3. Robinson MM, Zhang X. The world medicines situation 2011. Traditional medicines: global situation, issues and challenges. Geneva: World Health Organization; 2011.

4. Bannerman RH, Burton J, Chen WC. Traditional medicine and health care coverage: a reader for health administrators and practitioners. Geneva: World Health Organization; 1983.

5. Aziz M, Adnan M, Khan A, Shahat A, Al-Said M, Ullah R. Traditional uses of medicinal plants practiced by the indigenous communities at Mohmand agency, FATA. Pakistan. J Ethnobiol Ethnomed. 2018;14(2):2-16. https://doi. org/10.1186/s13002-017-0204-5.

6. Tang C, Zhao CC, Yi H, Geng ZJ, Wu XY, Zhang Y, Liu Y, Fan G. Traditional Tibetan medicine in cancer therapy by targeting apoptosis pathways. Front Pharmacol. 2020;11. https://doi.org/10.3389/fphar.2020.00976.

7. Liu C, Fan FF, Li XH, Wang WX, Tu Y, Zhang Y. Elucidation of the mechanisms underlying the anti-cholecystitis effect of the Tibetan medicine "Dida" using network pharmacology. Trop J Pharmaceut Res. 2020;19(9): 1953-61. https://doi.org/10.4314/tjpr.v19i9.22.

8. Zhao MM, Wang KR, Gu R, Zhong SH. A comparative study on shared-use medicines in Tibetan and Chinese medicine. J Ethnobiol Ethnomed. 2019; 15(1). https://doi.org/10.1186/s13002-019-0320-5.

9. Xiong Y, Sui XY, Ahmed S, Zhi W, Long CL. Ethnobotany and diversity of medicinal plants used by the Buyi in eastern Yunnan. China. Plant Diversity. 2020;42(6):401-14. https://doi.org/10.1016/j.pld.2020.09.004.

10. Mandakh U, Battseren M, Ganbat D, Ayanga T, Adiya Z, Borjigidai A, Long CL. Folk nomenclature of plants in Cistanche deserticola-associated community in South Gobi, Mongolia. Plant Diversity. 2020;42(6):434-42. https://doi.org/10.1016/j.pld.2020.09.008.

11. Zhang C, Chongsuvivatwong V, Keawpradub N, Lin YF. Analysis of prescription database extracted from standard textbooks of traditional Dai medicine. J Ethnobiol Ethnomed. 2012;8(1):34. https://doi.org/10.1186/174 6-4269-8-34.

12. Otieno J, Abihudi S, Veldman S, Nahashon M, van Andel T, de Boer HJ. Vernacular dominance in folk taxonomy: a case study of ethnospecies in medicinal plant trade in Tanzania. J Ethnobiol Ethnomed. 2015;11(1):10. https://doi.org/10.1186/1746-4269-11-10.

13. Luczaj L, Koncic MZ, Milicevic T, Dolina K, Pandza M. Wild vegetable mixes sold in the markets of Dalmatia (southern Croatia). J Ethnobiol Ethnomed. 2013;9(1):2. https://doi.org/10.1186/1746-4269-9-2.

14. Luo BS, Liu YJ, Liu B, Liu SZ, Zhang BX, Zhang LH, Lin CR, Liu Y, Kennelly EJ, Guo ZY, Long CL. Yao herbal medicinal market during the Dragon Boat Festival in Jianghua County, China. J Ethnobiol Ethnomed. 2018;14(1):61. https://doi.org/10.1186/s13002-018-0260-5.

15. Jin B, Liu YJ, Xie JX, Luo BS, Long CL. Ethnobotanical survey of plant species for herbal tea in a Yao autonomous county (Jianghua, China): results of a 2year study of traditional medicinal markets on the Dragon Boat Festival. J Ethnobiol Ethnomed. 2018;14(1). https://doi.org/10.1186/s13002-018-0257-0.

16. Lee SW, Mao CJ, Pei SJ. Ethnobotanical survey of medicinal plants at periodic markets of Honghe Prefecture in Yunnan Province. SW China. J Ethnopharmacol. 2008;117(2):362-77. https://doi.org/10.1016/j.jep.2008.02. 001.

17. Zhang KY, Gao C, Rao WX, Yin HX. Ethnobotanical study on medicinal herb market during Drogon Boat Festival in Puer, Yunann, China. Bangladesh J Bot. 2019;48(3):733-44

18. Li CY. Culture of Dragon Boat Festival in Zhuang nationality in Jingxi. J Hubei Correspondence Univ. 2017;30(21):80-2.

19. Zhang LP. Investigates on Chuanqing people folk culture and art festival-based on the perspective of the traditional sports culture. J Guiyang Univ (Social Science ). 2017;12(06):63-5. https://doi.org/10.3969/j.issn.1673-6133.

20. Lu JN, Zhang HL, Ren Z, Wang QY, Liu YB, Li YX, He GL, Guo JX, Zhao J, Hu R, Wei LH, Chen G, Huang J, Wang C-C. Genome-wide analysis of unrecognised ethnic group Chuanqing people revealing a close affinity with Southern Han Chinese. Ann Hum Biol. 2020;47(5):465-71. https://doi. org/10.1080/03014460.2020.1782470.

21. Liu YB, Zhang $H$, He GL, Ren Z, Zhang HL, Wang QY, Ji JY, Yang MQ, Guo JX, Yang XM, Sun J, Ba J, Peng D, Hu R, Wei LH, Wang CC, Huang J. Forensic features and population genetic structure of Dong, Yi, Han, and Chuanqing human populations in Southwest China inferred from insertion/deletion Markers. Front Genet. 2020;11. https://doi.org/10.3389/ fgene.2020.00360.

22. Liu CX, Xie YG, Lu WQ, Bi N, Wu CP. Preliminary study on relationship between karst vegetation distribution and mountain climate in Northwestern Guizhou. Forest Inventory and Planning. 2008;33(4):41-5. https://doi.org/10.3969/j.issn.1671-3168.2008.04.011.

23. Zou TC. Studies on survey and utilization of medicinal plant germplasm resources for sustainable development in Guizhou, China. J Pharm Pract (National Sciences). 2001:19(2):1-11.

24. Chen Q, Ke LP, Cheng F, Wang G. Analysis of the best meteorological conditions of Gaoshan organic tea in Nayong County. South China Agric. 2017;11(23):3-4. https://doi.org/10.19415/j.cnki.1673-890x.2017.23.002. 
25. Wu ZY, Raven PH, Hong DY. Flora of China. Beijing: Science Press; and St. Louis: Missouri Botanical Garden Press; 2010.

26. Guizhou Flora Editorial Board. Flora of Guizhou (Vol. 1-10). Guiyang: Guizhou People's Publishing House; 1982.

27. Chinese Pharmacopoeia Commission. The pharmacopoeia of the People's Republic of China 2020 Edition. Beijing: Chinese Medical Science Press; 2020.

28. Guizhou Medical Products Administration. The Quality Standard of TCM and National Medicine in Guizhou Province. Guiyang: Guizhou Science and Technology Publishing House; 2003.

29. The information system of Chinses Rare and Endangerous Plants. 2013. http://www.iplant.cn/rep/protlist. Accessed 4 March 2020.

30. Albuquerque UP, Lucena RFP, Monteiro JM, Florentino ATN. Evaluating two quantitative ethnobotanical techniques. Ethnobotany Res App. 2006;4:5160. https://doi.org/10.17348/era.4.0.51-60.

31. Tardío J, Pardo-de-Santayana M. Cultural importance indices: a comparative analysis based on the useful wild plants of southern Cantabria (Northern Spain). Econ Bot. 2008;62(1):24-39. https:/doi.org/10.1007/s12231-007-9004-5.

32. Phumthum $M$, Srithi $K$, Inta A, Junsongduang A, Tangjitman $K$, Pongamornkul W, Trisonthi C, Balslev H. Ethnomedicinal plant diversity in Thailand. J Ethnopharmacol. 2018;214:90-8. https://doi.org/10.1016/.j.ep.201 7.12.003.

33. Phumthum M, Balslev H, Kantasrila R, Kaewsangsai S, Inta A. Ethnomedicinal plant knowledge of the Karen in Thailand. Plants Basel. 2020;9, 9(7, 7). https://doi.org/10.3390/plants9070813, Ethnomedicinal Plant Knowledge of the Karen in Thailand

34. Phumthum M, Balslev H, Barfod AS. Important medicinal plant families in Thailand. Front Pharmacol. 2019;10. https://doi.org/10.3389/fphar.2019.01125.

35. Panyadee $P$, Balslev $H$, Wangpakapattanawong $P$, Inta A. Medicinal plants in homegardens of four ethnic groups in Thailand. J Ethnopharmacol. 2019; 239:14. https://doi.org/10.1016/j.jep.2019.111927.

36. Libman A, Bouamanivong S, Southavong B, Sydara K, Soejarto DD. Medicinal plants: an important asset to health care in a region of Central Laos. J Ethnopharmacol. 2006;106(3):303-11. https://doi.org/10.1016/j.jep.2 005.11.034.

37. Dubost JM, Phakeovilay C, Her C, Bochaton A, Elliott E, Deharo E, Xayvue M, Bouamanivong S, Bourdy G. Hmong herbal medicine and herbalists in Lao PDR: pharmacopeia and knowledge transmission. J Ethnobiol Ethnomed. 2019;15(1):27. https://doi.org/10.1186/s13002-019-0307-2.

38. Elliott E, Chassagne F, Aubouy A, Deharo E, Souvanasy O, Sythamala P, Sydara K, Lamxay V, Manithip C, Torres JA, Bourdy G. Forest fevers: traditional treatment of malaria in the southern lowlands of Laos. J Ethnopharmacol. 2020;249:35. https://doi.org/10.1016/j.jep.2019.112187.

39. Lee C, Kim S-Y, Eum S, Paik J-H, Tran The B, Darshetkar AM, Choudhary RK, Do Van H, Bui Hong Q, Nguyen Trung T et al. Ethnobotanical study on medicinal plants used by local Van Kieu ethnic people of Bac Huong Hoa nature reserve, Vietnam. J Ethnopharmacol 2019,231:283-294. doi: https:// doi.org/10.1016/j.jep.2018.11.006.

40. Xuan-Minh-Ai N, Bun S-S, Ollivier E, Thi-Phuong-Thao D. Ethnobotanical study of medicinal plants used by K'Ho-Cil people for treatment of diarrhea in Lam Dong Province. Vietnam. J Herbl Med. 2020;19:100320. https://doi. org/10.1016/j.hermed.2019.100320.

41. Kyaw YMM, Bi Y, Oo TN, Yang X. Traditional medicinal plants used by the Mon people in Myanmar. J Ethnopharmacol. 2021;265:113253. https://doi. org/10.1016/j.jep.2020.113253.

42. Ong HG, Kim Y-D. Medicinal plants for gastrointestinal diseases among the Kuki-Chin ethnolinguistic groups across Bangladesh, India, and Myanmar: a comparative and network analysis study. J Ethnopharmacol. 2020;251: 112415. https://doi.org/10.1016/j.jep.2019.112415.

43. Ong HG, Ling SM, Win TTM, Kang D-H, Lee J-H, Kim Y-D. Ethnomedicinal plants and traditional knowledge among three Chin indigenous groups in Natma Taung National Park (Myanmar). J Ethnopharmacol. 2018;225:136-58. https://doi.org/10.1016/j.jep.2018.07.006

44. Zhou CX. A study on the national identity of Chuanqing people. Guiyang Guizhou Minzu University; 2013.

45. Li ZF. Division of karst landform in Guizhou. Guizhou Geology. 2011;28(3): 177-181,234. https://doi.org/10.3969/j.issn.1000-5943.2011.03.005.

46. Li JH, Zhang LH. Application of tissue culture and mycorrhizal technology of medicinal orchid plants for seeding production. Seed. 2015;34(8):133-4.

47. Wang $L S$, Jia $Y$, Zhang $X C$, Qin $H N$. Overview of higher plant diversity in China. Biodivers Sci. 2015;23(2):217-24. https://doi.org/10.17520/biods.2015049.
48. Bensky D, Gamble A. Chinese herbal medicine (Materia Medica). Seattle: Eastland Press; 1986. p. 723.

49. Chen SL, Liu CX, Zhang TJ, Liu A, Zhu GW, Wang YL, Chen CQ, Zhang HB, Xiao XF, Huang YH. Ideas and suggestions on CMM decoction inheritance based on CMM quality markers and traditional usage. Chinese Traditional Herbal Drugs. 2019;50(19):4519-28 https://10.7501/j.issn.0253-2670.2019.19. 001.

50. Wang S, Guo Z. Talking about the cause and solution of some medicinal liquor precipitation. Chin J Chin Mater Med. 1991;05.

51. Cai Y, Wu RX, Lan L, Miao ZW, Xue M. Inpatient disease spectrum and resource consumption in China, 2011-2015. Chin J Health Stat. 2017;34(2): 298-9.

52. Hu R, Lin C, Xu W, Liu Y, Long C. Ethnobotanical study on medicinal plants used by Mulam people in Guangxi, China. J Ethnobiol Ethnomed. 2020; 16(1). https://doi.org/10.1186/s13002-020-00387-z.

53. Li SR. Neutral Group, Border Residents and Others. Ethnogenesis of Chuanqing people and ethnic identity. Qinghai J Ethnol. 2017;28(1):61-3.

54. Wang QH, Gao C, Li M, Yao RY, Yin HX. Ethnobotanical study on medicinal plants used by Chuanqing people. J Chin Med Mater. 2020;43(7):1597-602.

55. Zhou XR, Xia WX, Zhang YW, Ma JH, Zhou H, Dong L, Fu XY. Cynanchum paniculatum (Bunge) Kitag. ex H. Hara: a review of its ethnopharmacology, phytochemistry and pharmacology. J Ethnopharmacol. 2020;260:19.

56. Zhang JP, Tian XH, Yang YX, Liu QX, Wang Q, Chen LP, Li HL, Zhang WD. Gleditsia species: an ethnomedical, phytochemical and pharmacological review. J Ethnopharmacol. 2016;178:155-71. https://doi.org/10.1016/j.jep.201 5.11.044.

57. Li J. Traditional Chinese medicinal composition used for treating diarrhea, comprises Sanguisorba officinalis, rhizoma coptidis, herba artemisiae, rhizome, Atractylodes japonica, burdock, nutgrass galingale rhizome and rhizoma cyperi. In.: Suzhou Tianling Chinese Herbal Slices Co.

58. Gao Z, Ma J, Li Y. Feed additive used for e.g. suckling pigs for preventing diarrhea, and enhancing immunity, comprises montmorillonite, dried orange peel, Sanguisorba officinalis, radix scutellariae, radix isatidis, Perilla leaf and starch. Chinese patent, CN109548975-A.

59. Luo Y. Medicinal composition used for treating white diarrhea of chicken, comprises fried Sanguisorba officinalis, radix codonopsitis, radix astragali, lagehead Atractylodes, Pulsatilla root, radix scutellariae and radix sophorae flavescentis. Chinese patent, CN106309662-A.

60. WorldAtlas. 2021. https://www.worldatlas.com/. Accessed 31 January 2021.

61. He P. A brief review on the Miao's immigration to Southeast Asian. Guizhou Ethnic Stud. 2005;25(101):137-41.

62. He P. Formation and ethnic group identity of cross-border ethnic groups between Southeast China and Southeast Asian. Guangxi Ethnic Stud. 2009;3 122-8. https://doi.org/10.3969/j.issn. 1004-454X.2009.03.020

63. Zhu LZ. China's medicine exchange with Southeast Asia in Sung Dynasty. Guangzhou: Jinan University; 2003.

64. Ooi GL. Chinese medicine in Malaysia and Singapore - the buiness of heaing. Am J Chin Med. 1993;21(3-4):197-212. https://doi.org/10.1142/S01 92415X93000236.

65. Local annals compilation committee of Nayong County, Guizhou Province. Annals of Nayong County.Guiyang:Guizhou People's Publishing House;1984.

66. China Intangible Cultural Heritage Network.China Intangible Cultural Heritage Digital Museum. 2018. http://www.ihchina.cn/. Accessed 15 January 2021.

\section{Publisher's Note}

Springer Nature remains neutral with regard to jurisdictional claims in published maps and institutional affiliations. 